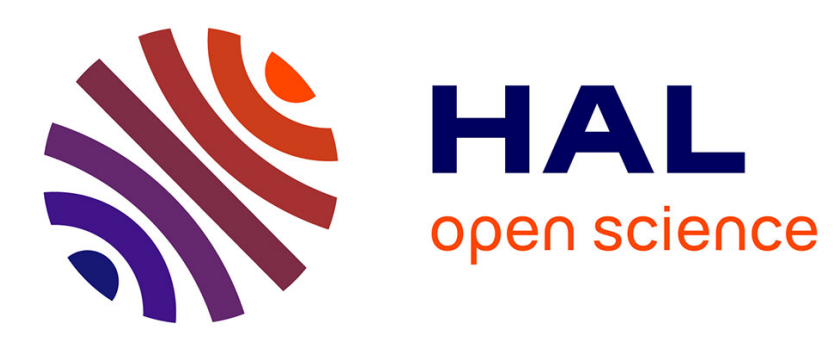

\title{
Host-Guest Compounds Oligomeric Cucurbituril Complexes: from Peculiar Assemblies to Emerging Applications
}

Xue Yang, Ruibing Wang, Anthony Kermagoret, David Bardelang

\section{- To cite this version:}

Xue Yang, Ruibing Wang, Anthony Kermagoret, David Bardelang. Host-Guest Compounds Oligomeric Cucurbituril Complexes: from Peculiar Assemblies to Emerging Applications. Angewandte Chemie International Edition, 2020, 132, pp.2-15. 10.1002/anie.202004622 . hal-02972332

\section{HAL Id: hal-02972332 \\ https://hal-amu.archives-ouvertes.fr/hal-02972332}

Submitted on 23 Oct 2020

HAL is a multi-disciplinary open access archive for the deposit and dissemination of scientific research documents, whether they are published or not. The documents may come from teaching and research institutions in France or abroad, or from public or private research centers.
L'archive ouverte pluridisciplinaire $\mathbf{H A L}$, est destinée au dépôt et à la diffusion de documents scientifiques de niveau recherche, publiés ou non, émanant des établissements d'enseignement et de recherche français ou étrangers, des laboratoires publics ou privés. 


\title{
Oligomeric Cucurbituril Complexes: from Peculiar Assemblies to Emerging Applications.
}

\author{
Xue Yang, ${ }^{[a]}$ Ruibing Wang, ${ }^{* b]}$ Anthony Kermagoret, ${ }^{*}[a]$ and David Bardelang ${ }^{*}[a]$
}

\begin{abstract}
Proteins are an endless source of inspiration. By carefully tuning the amino-acid sequence of proteins, nature made them evolve from primary to quaternary structures, a property specific to protein oligomers and often crucial to accomplish their function. On the other hand, the synthetic macrocycles cucurbiturils (CBs) have shown outstanding recognition properties in water, and a growing number of (host) $)_{n}$ (guest) $)_{n}$ supramolecular polymers involving CBs have been reported. However, the burgeoning field of discrete (n:n) host:guest oligomers has just started to attract attention. While 2:2 complexes are the major oligomers, 3:3 and up to $6: 6$ oligomers have been described, some associated with emerging applications, specific to the $(n: n)$ arrangements. Design rules to target $(n: n)$ host:guest oligomers are proposed toward new advanced host:guest systems.
\end{abstract}

\section{1- Introduction}

Protein homo- and hetero-oligomers are fascinating molecular architectures, not only because of their symmetric structures, but also due to the new functions accessible in their aggregated state..$^{[1-3]}$ The hemoglobin tetramer is an archetype of such a protein oligomer, by which aggregation has enabled to improve oxygen transport. ${ }^{[4,5]}$ Helicases are circular protein oligomers, unwinding DNA strands during cell replication cycles ${ }^{[6]}$ and poreforming proteins (such as $\mathrm{T}$ lymphocyte perforin) ${ }^{[7]}$ circularly assemble to form pores on target cell membranes. ${ }^{[8]}$ When two or more different proteins aggregate, hetero-oligomers of precise shape can form, such as nicotinic acetylcholine receptors arranged to form ionic channels. ${ }^{[9,}{ }^{10]}$ However, mimicking the faculties of proteins to produce precisely defined oligomers from small building-blocks has remained elusive for a long time. ${ }^{[11,12]}$ More generally, organizing small molecules in precisely-defined architectures in the $8-100 \mathrm{~nm}$ scale remains a tremendous challenge..$^{[13]}$

For the last two decades, cucurbit $[n]$ urils $(\mathrm{CB}[n] \mathrm{s}, \mathrm{n}=5-8,10,13-$ 15) have attracted a lot of attentions due to their excellent recognition properties in water. ${ }^{[14-18]}$

[a] X. Yang, Dr. A. Kermagoret, Dr. D. Bardelang, Aix Marseille Univ, CNRS, ICR, Marseille, France

E-mail: anthony.kermagoret@univ-amu.fr

E-mail: david.bardelang@univ-amu.fr

[b] Prof. R. Wang

State Key Laboratory of Quality Research in Chinese Medicine, Institute of Chinese Medical Sciences, University of Macau, Taipa, Macau, China

E-mail: rwang@um.edu.mo
Xue Yang earned her Master's degree from the University of Macau (China) in 2017. She is currently pursuing her $\mathrm{PhD}$ on the supramolecular chemistry of cucurbiturils at Marseille University.

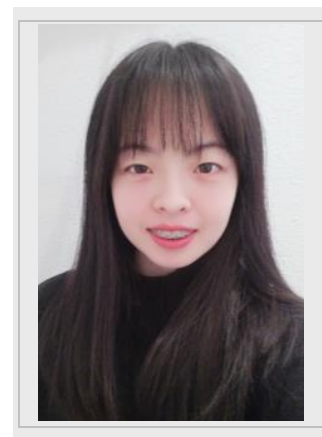

Ruibing Wang got his $\mathrm{PhD}$ degree in Organic Chemistry from Queen's University (Canada) in 2007. After a brief stay as a post-doc at Queen's University, he moved to the National Research Council of Canada as a Research Associate for two years. He then worked in biotechnology industry in Ottawa for 5 years, and joined the University of Macau as a P. I. in Pharmaceutical Sciences since late 2014. His research is focused on supramolecular medicine and pharmaceutics.

Anthony Kermagoret got his $\mathrm{PhD}$ from the University of Strasbourg (France) in 2007. He then developed various research projects in organometallic and polymer chemistry at the University of Paris-Sud (France), RWTH (Germany), University Lyon I (France) and University of Liege (Belgium). In 2015, he became associate professor at Aix-Marseille University (France). His research focus on macromolecular engineering, organometallic and supramolecular chemistry.

David Bardelang got his $\mathrm{PhD}$ in Marseille (France) in 2005 about the use of cyclodextrins in spin trapping experiments. He then moved to Birmingham (UK) working on helicates with Mike Hannon as a post-doc before moving to Canada for two years working on peptides, gels and cucurbiturils with Chris Ratcliffe and John Ripmeester at NRC. Since 2009, he is a researcher at CNRS in Marseille working on the supramolecular chemistry of cucurbiturils.
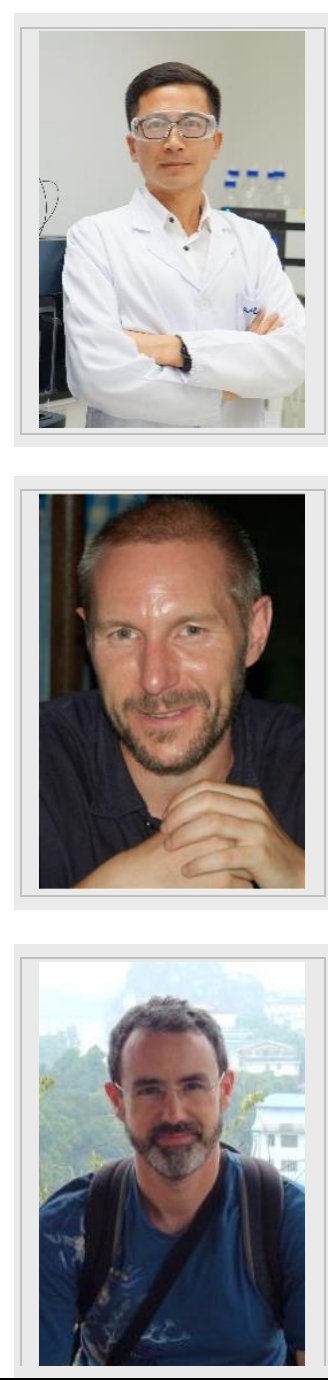

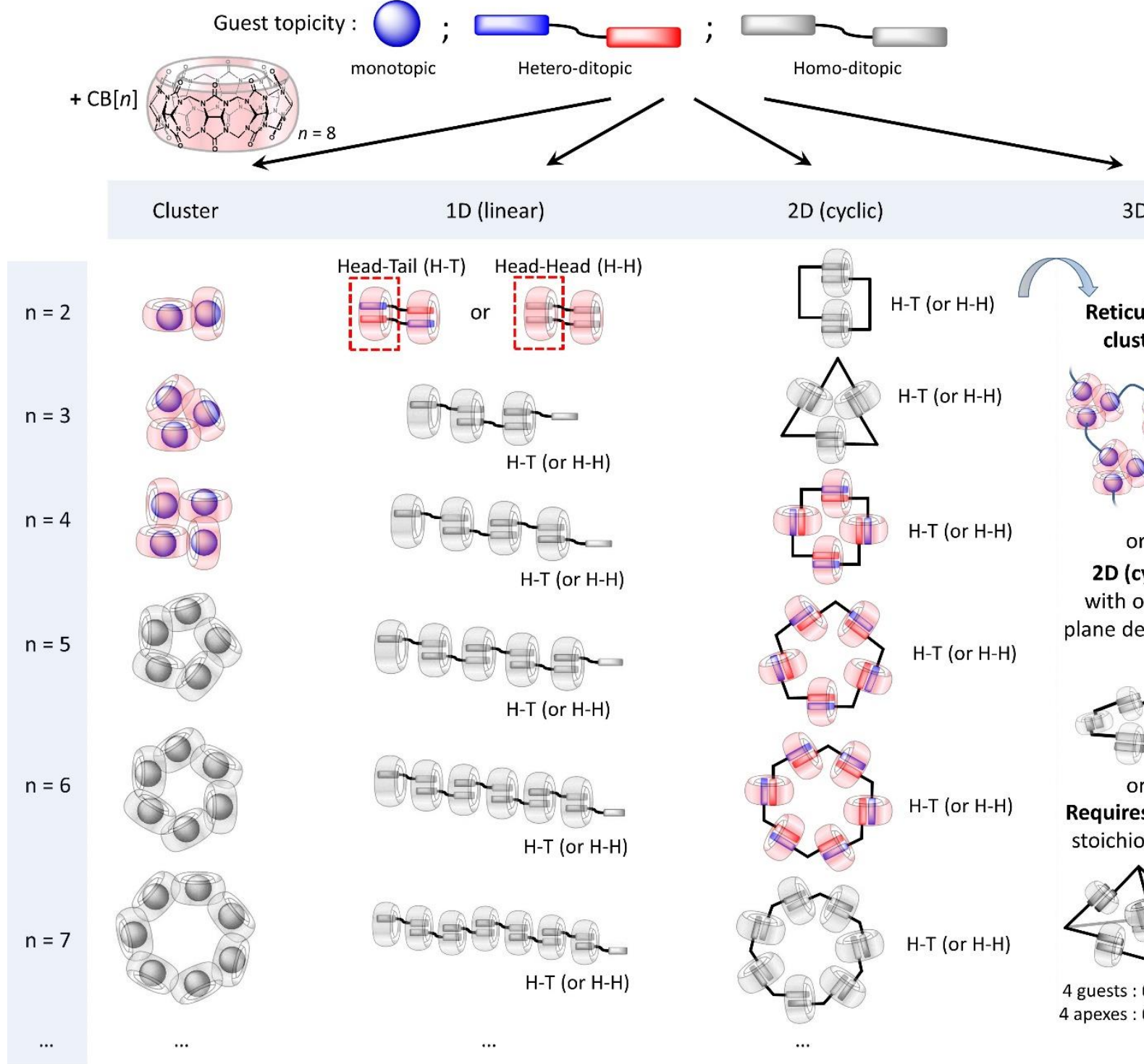

Figure 1. Groups of oligomeric assemblies comprising an identical number "n" of cucurbituril hosts and guests (example with CB[8]). Colored structures are described while greyscale assemblies are not reported to the best of our knowledge. Note the group of short-oligomers (linear assemblies), the problem of mismatches for end-groups and the possible advantage upon cyclization. Besides monotopic (one site of binding) guests (cluster column), both hetero-ditopic (two different sites of binding) and homo-ditopic (two identical sites of binding) guests have been used to produce a rapidly growing family of (Host) :(Guest) $_{n}$ superstructures while 3D assemblies remain hard to do.

While cyclodextrins ${ }^{[19]}$ or calixarenes ${ }^{[20]}$ have their own merits, host•guest complexes of $\mathrm{CB}[n]$ are characterized by high binding constants in water, ensuring robustness of target assemblies in large domains of concentrations and improving predictability and switchability of advanced architectures. ${ }^{[21,22]}$ Indeed, one of the main driving forces for $\mathrm{CB}$ binding is based on the release of "high-energy" water molecules from the cavity of the host upon guest binding. ${ }^{[23]}$ When cations are grafted on relevant guests, ion-dipole interactions are combined with hydrophobic effect and binding constants typically reach $10^{9-12} \mathrm{M}^{-1},{ }^{[17]}$ and up to $10^{17} \mathrm{M}$ ${ }^{1 .}{ }^{[24]}$ These considerations mainly account for the vast majority of guest molecules tightly binding in $\mathrm{CB}[6], \mathrm{CB}[7]$ or $\mathrm{CB}[8]$ based on a $1: 1$ stoichiometry. However, for large $\mathrm{CBs}$ such as $\mathrm{CB}[8]$ or $\mathrm{CB}[10]$, more than 1 guest can be accommodated in the host. ${ }^{[16}$, ${ }^{18]}$ In 2001, ${ }^{[25]} \mathrm{CB}[8]$ was reported to be able to include an electronpoor $1^{\text {st }}$ guest $(A)$, leaving enough room for a $2^{\text {nd }}$ electron-rich guest (D) to come in (Figure 1 red dashed lines, H-T). This donor- acceptor D-A assembly has laid down the foundations for a large and rapidly growing subfield of the $\mathrm{CB}$ chemistry. ${ }^{[14-18,26]}$ including the possibility to "supramolecularly click" various compounds such as peptides, ${ }^{[27]}$ proteins, ${ }^{[28]}$ dendrimers ${ }^{[29,30]}$ or polymers. ${ }^{[31]}$ However, when large-cavity CBs are mixed with ditopic guests, supramolecular polymers usually form, ${ }^{[32,33]}$ but sometimes, oligomeric (host) ${ }_{n}$ (guest) ${ }_{n}$ assemblies are observed (Figure 1). Understanding why precise oligomers form could enable access to precise shape (and function) oligomers by a supramolecular approach that would dramatically reduce synthetic efforts compared to covalent analogues, while imparting at the same time the dynamic features typical of supramolecular systems. Hence, design rules toward controlled supramolecular oligomers could be of great benefit to the advance of functional assemblies in water, and recent papers outline increased degrees of control over these architectures (Figure 2), and on their properties. 


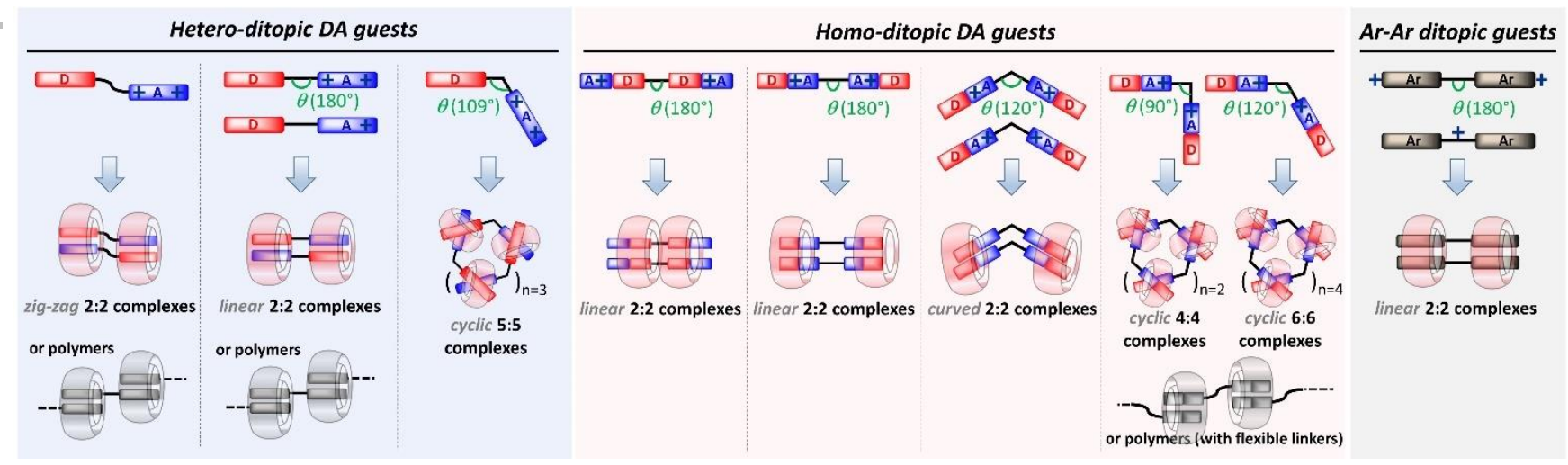

Figure 2. Main ditopic guest molecules affording oligomeric, or polymeric assemblies with $\mathrm{CB}$ [8]. The $\mathrm{H}$-H (Head-to-Head) versus $\mathrm{H}$-T (Head-to-Tail) arrangements are important, as flexibility, rigidity, or angles between building-blocks. The number and the place of cationic charges are also important as they are required to improve solubility and binding to $\mathrm{CB}$, and also affect the outcome of the assembly in water. Most discrete oligomers are $2: 2$ complexes, the variety of which is rapidly increasing, and cyclic oligomers are an emerging class of supramolecular assemblies. ( $D=$ donor; $A=$ acceptor). These motifs can tentatively be used as guiding principles to the design of oligomeric cucurbiturils complexes.

\section{2- Discrete Cucurbituril n:n complexes}

Beside their size ( $\mathrm{n}$ value), the main properties related to oligomeric structures are their shape, and their functional groups. Clusters, 1D, 2D or 3D assemblies can be designed (Figure 1) with imparted functions, or additional functions created by a synergy between building-blocks. For these 4 families, we have found a few cases for which appropriate guest design enabled formation of discrete oligomers (Figure 2). Clusters, 1D and 2D assemblies have been reported, but 3D oligomers seem limited to reticulated cluster complexes, ${ }^{[34-36]}$ to cyclic $2 \mathrm{D}$ assemblies with out-of-plane deviations or for $n \neq m$ as shown by Euler in 1752 (the number of apexes is different from the number of edges for regular polyhedral, Figure 1 right). ${ }^{[37]}$ The difference between 1D and $2 \mathrm{D}$ assemblies (cyclic or any shape-persistent object lying in a plane) is very subtle and can sometimes only be inferred by the introduction of only one degree of freedom or one constrain (i. e. an angle) in a guest structure (Figure 2). Linear oligomers of precise length are hard to get experimentally because they tend to endlessly grow toward n:n supramolecular polymers or are in equilibrium with smaller or larger analogues. However, when a guest has end-groups that can intertwin to maximize stabilizing interactions, 2:2 complexes can form. Comparatively, cyclic oligomers appear more difficult to get. These structures involve a folding of a growing oligomer up to cyclization. In the next sections we will present the main structures obtained with $\mathrm{CB}[8]$ from 2:2 to $6: 6$ complexes and their emerging properties.

\section{1- Concepts toward n:n oligomers}

In ditopic guests, the $\mathrm{A}$ and $\mathrm{D}$ blocks are connected covalently and still tend to strongly interact by facing each other when $\mathrm{CB}[8]$ is added. This "hetero-ditopic" strategy (Figure 2, clear bleu panel) is particularly efficient for the construction of dimers, oligomers or polymers when bis-pyridinium derivatives (A) such as viologens or dipyridyliumylethylenes are linked with flat polyaromatics (D) such as naphthalenes or anthracenes. ${ }^{[21,22,32,33]}$ The other "homoditopic" strategy (Figure 2, clear red panel) consists of assembling in a homo-dimer fashion two guest molecules possessing two $D$ and two A blocks in the cavity of $\mathrm{CB}[8]$. This strategy has also started to be widely used for the construction of supramolecular polymers. ${ }^{[38,39]}$ Finally, a $3^{\text {rd }}$ strategy has recently started to emerge (Figure 2, grey panel) for which di-aryl ditopic guests assemble into discrete homo-dimeric 2:2 complexes with $\mathrm{CB}[8]$ displaying more subtle interactions between the cationic charge of the guest and $\mathrm{CB}[8]$. This strategy also allowed to assemble cationic hydrophobic monomers into supramolecular polymers by aromatic $\pi$-stacking in the cavity of $\mathrm{CB}[8] .{ }^{[40,41]}$ Since $\mathrm{CB}[8]$ can accommodate two flat guests in its cavity, ditopic compounds possessing two guest parts can produce either 1:1 complexes, 2:2 complexes, n:n supramolecular oligomers or polymers ${ }^{[42]}$ depending on a balance of several factors such as molecular rigidity, angles between building-blocks, linker length, or the number and distribution of cationic charges on the guest (Figure 2), the impact of which is discussed hereafter.

\section{2- 2:2 complexes.}

\subsection{1. hetero-ditopic 2:2 complexes}

While 1D and 2D oligomers have started to be widely explored, cluster type 2:2 complexes have been seldom reported. [43]

Toward asymmetric 2:2 complexes. Hetero-ditopic compounds always lead to "Head-to-Tail" (H-T) assemblies with $\mathrm{CB}$ [8] (with few exceptions ${ }^{[44]}$ but the nature of the linker can control the outcome. The $1^{\text {st }}$ case of a 2:2 complex of $\mathrm{CB}[8]$ was hypothesized in 2002 by Kim and co-workers, and consisted of a viologen-naphthalene hetero-ditopic guest (Figure 3a). ${ }^{[45]}$ However, NMR data are more in line with a folded 1:1 complex. Later, Kim and co-workers explored the complexation of a similar guest but with a phenylene linker (Figure $3 b$ ) preventing intramolecular interactions in one CB[8]. The resulting "zig-zag" $2: 2$ complexes were in equilibrium with short $n: n$ oligomers, as suggested by DOSY. ${ }^{46]}$

Structural optimization of block A by replacing the 4,4'bipyridinium unit by a dipyridyliumylethylene allowed the authors to exclusively observe 2:2 complexes (Figure 3c). ${ }^{[47]}$ The new design involved a longer, rigid dication linked to a naphthalene 
group by the same linker possessing three degrees of rotational freedom. Besides a methoxy group on the naphthalene expected to have no influence on 2:2 complex formation, replacement of the rigid central phenylene of the linker by an alkene resulted in $1: 1$ complex formation. ${ }^{[47]}$

a)

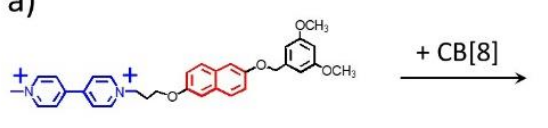

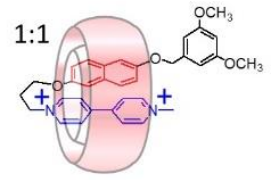

b)

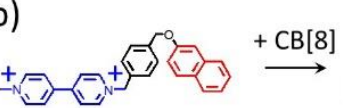

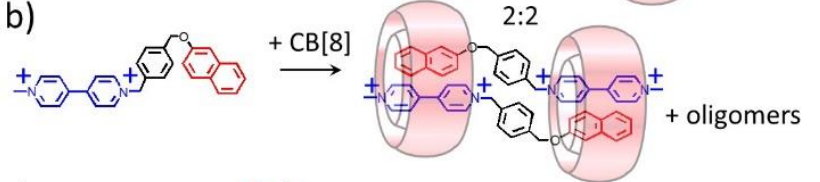
2:2

c)

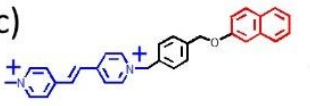

\section{$\stackrel{\mathrm{CB}[8]}{\longrightarrow}$}

d)

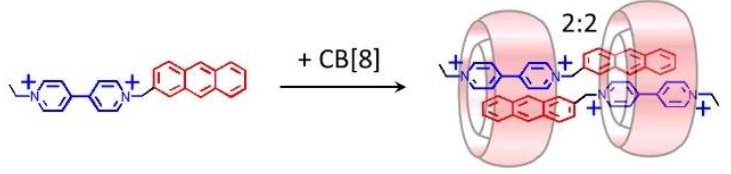

Figure 3. Examples of hetero-ditopic guests leading to $1: 1$ and "zig-zag" $2: 2$ complexes upon addition of $\mathrm{CB}[8]$.

The two complexation modes were studied by 1D and 2D NMR, mass spectrometry and molecular modelling. Evaluation of hydrodynamic radii by DOSY experiments further supported formation of the proposed 1:1 and 2:2 structures in solution. ${ }^{\left[{ }^{[7]}\right.} \mathrm{A}$ very similar guest with a shorter linker produced a totally different assembly (vide supra, 5:5 complex section). ${ }^{[48]}$ Zhang and coworkers prepared a guest with an anthracene $D$ unit linked to a viologen $A$ group by a methylene linker (Figure $3 d$ ). While the resulting hetero-ditopic guest led to a well-defined 2:2 complex, the synthesis of a symmetrical bis(anthracene-viologene) with a butyl linker allowed formation of a $\mathrm{CB}[8]$-based poly(2:2) supramolecular polymer. ${ }^{[49]}$ Kathiresan et al. similarly exploited this concept using a hetero-multitopic viologen-naphthalene guest to prepare $\mathrm{CB}[8]$ supramolecular polymers. ${ }^{[50]}$

Asymmetric 2:2 complexes of fluorescent dyes. Mohanty, Bhasikuttan and co-workers studied the $\mathrm{CB}[8]$ complexation of Thioflavin $T,{ }^{[51]}$ a well-known dye, widely used in investigations related to Alzheimer's disease. ${ }^{[52]}$ The addition of $\mathrm{CB}[8]$ to Thioflavin T generated a H-T 2:2 complex with all-included methyl groups (Figure 4a). This constrained assembly strongly increased the fluorescence of the dye by slowing down rotational motions thereby decreasing non radiative decay pathways and increasing quantum yields. This complexation mode could be changed by $\mathrm{Ca}^{2+}$ cations to 2:1 complexes, resulting in fluorescence drops. ${ }^{[51]}$ Mohanty, Bhasikuttan and co-workers extended this work to the complexation of Thiazole Orange (TO) by $\mathrm{CB}[8]$ and observed the formation of a H-T 2:2 complex (Figure 4b) with a fluorescent emission, improved by 1700 fold compared to that of TO alone. ${ }^{[53]}$

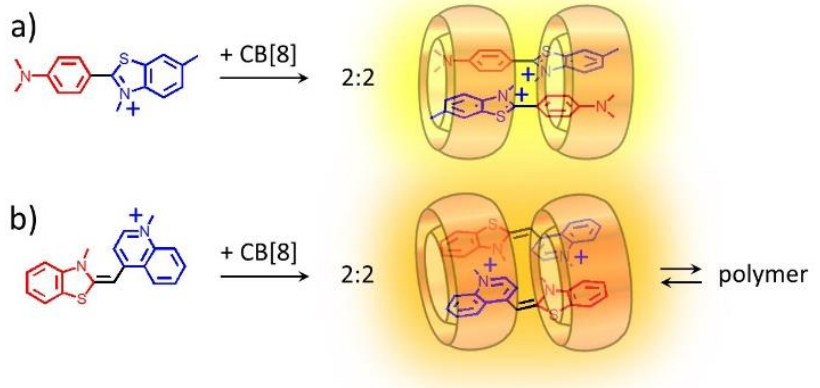

Figure 4. Formation of 2:2 complexes of Thioflavin $\mathrm{T}$ (a) and Thiazole Orange (b) after addition of $\mathrm{CB}[8]$ in water.

However, Pang and co-workers observed a dynamic equilibrium between 2:2 complexes and supramolecular polymers at higher concentrations of TO and $\mathrm{CB}[8] .{ }^{[54]}$

In 2019, Schalley and coworkers studied the complexation of a series of linear, aryl-pyridinium derivatives by $\mathrm{CB}$ [8] (Figure 5), which led to H-T 2:2 complexes. ${ }^{[55]}$ a)

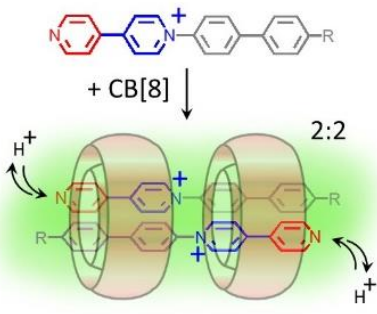

b)

\begin{tabular}{l|c|c|}
\hline $\mathbf{R}$ & $\varphi_{\text {Alone }}$ & $\varphi_{\text {2:2 complex }}$ \\
\hline $\mathrm{H}$ & $03 \%$ & $82 \%$ \\
$\mathrm{CHO}$ & $26 \%$ & $80 \%$ \\
$\mathrm{COCH}_{3}$ & $17 \%$ & $78 \%$ \\
$\mathrm{CH}_{3}$ & $04 \%$ & $42 \%$ \\
$\mathrm{Br}$ & $02 \%$ & $05 \%$ \\
$\mathrm{CH}_{2} \mathrm{OH}$ & $13 \%$ & $43 \%$ \\
& & \\
\end{tabular}

Figure 5. 2:2 complexes of aryl-pyridinium guests and $\mathrm{CB}[8]$ (a) with corresponding improvements of fluorescence quantum yields (b).

The authors found that double binding using two $\mathrm{CB}[8]$ dramatically restricted rotational freedom of the guest subunits resulting in improved fluorescence. The $\mathrm{pH}$-responsiveness of the terminal pyridine groups introduced further tunability in fluorescence properties.

Negative $\mathrm{p} K_{2}$ shift in 2:2 complexes. In parallel, Yin et al. found that, a linear and rigid imidazole derivative of methyl-viologen assembled as a 2:2 complex with $\mathrm{CB}[8]$ (Figure 6), exhibiting an unusual, negative $\mathrm{p} K_{\mathrm{a}}$ shift. ${ }^{[56]}$

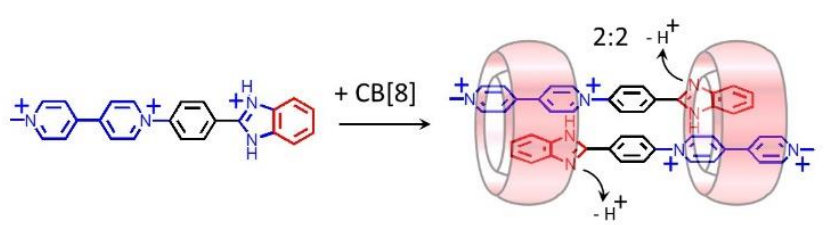

Figure 6. Negative $\mathrm{p} K_{\mathrm{a}}$ shift by $2: 2$ complex formation with $\mathrm{CB}[8]$.

This result is counter-intuitive as the very large majority of $C B$ complexes show positive $\mathrm{p} K_{\mathrm{a}}$ shift, but could be rationalized by the combination of binding strength, rigidity of the complex, shielded imidazoles less prone to be protonated (contrasting with the $1: 1$ complex with $\mathrm{CB}[7]),{ }^{[57]}$ and the total charge of the complex rising to $6+$ if protonated. This negative $p K_{a}$ shift was exploited to trigger host:guest swapping in water according to a cascade of supramolecular events, reminiscent of some biological systems. 
Photocontrol of asymmetric 2:2 complexes. In efforts to impart supramolecular systems with stimuli by which they could respond to, Scherman and co-workers prepared a hetero-ditopic guest with a photoresponsive azobenzene. ${ }^{[58]}$ With $\mathrm{CB}[8]$, this guest preferentially formed a 2:2 complex, in equilibrium with a supramolecular polymer. Light irradiation led to $\mathrm{E} \rightarrow \mathrm{Z}$ isomerization of the azobenzene group causing the partial reorganization of 2:2 complexes in 1:1 complexes. Later, Liu, Zhang and co-workers prepared a difluorinated analogue responding similarly to light (Figure 7). ${ }^{[59]}$ a)

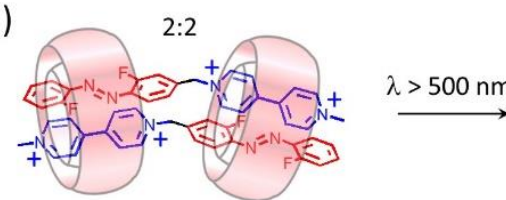

b)

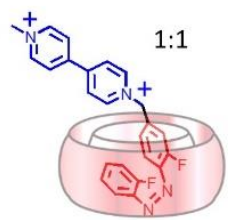

Figure 7. Light-triggered trans-cis isomerization reorganizing 2:2 complexes into $1: 1$ complexes.

$\mathrm{CB}[8]$ mediated supramolecular polymerization could then be controlled by light using bis(azobenzene-viologen) guests. ${ }^{[58,59]}$ Conformational control in 2:2 complexes. Following the $3^{\text {rd }}$ strategy (Figure 2), Masson and co-workers reported an extensive work about platinum-terpyridyl derivatives with $\mathrm{CB}[8]$ and showed that 2:2 complexes formed in water with equilibria involving $\mathrm{H}-\mathrm{H}$ and $\mathrm{H}-\mathrm{T}$ arrangements (Figure 8a), ${ }^{[4]}$ the proportion of which could be controlled both kinetically and thermodynamically. Extending this work, Masson and co-workers prepared bis-Pt-terpyridyl guests linked by two types of cores (Figure $8 \mathrm{~b}$ ) and corresponding homoquaternary 2:2 complexes with $\mathrm{CB}[8]{ }^{[60]}$ In a $1^{\text {st }}$ self-sorting experiment, the linear thread with a naphthalene group, functionalized on positions 2 and 6 templated the formation of a heteroquaternary 2:2 complex with a constrained linear $2^{\text {nd }}$ guest (Figure $8 b$ ). However, when the naphthalene was substituted in positions 2 and 7, imposing an angle in the shape of the guest, curved heteroquaternary $2: 2$ complexes were observed (Figure 8c).

a)

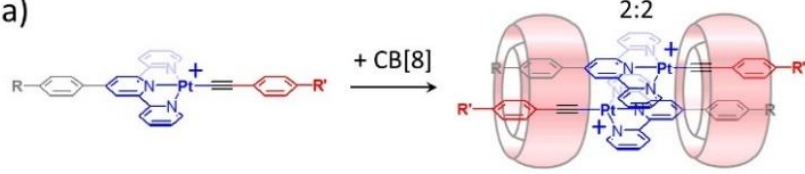

b)

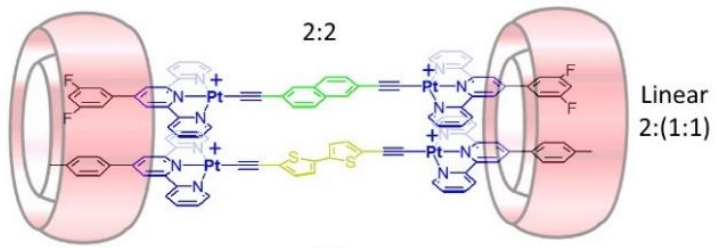

c)

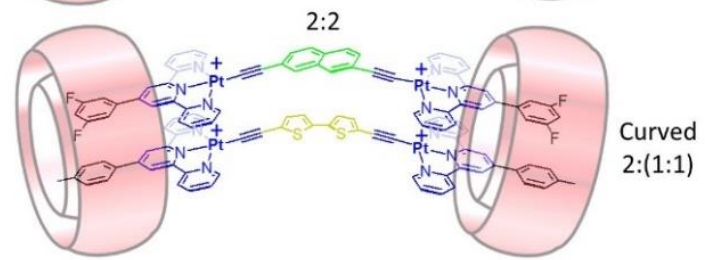

Figure 8. 2:2 complexes (a) based on $\mathrm{CB}[8]$ and platinum-terpyridyl complexes $\left(\mathrm{R}=4\right.$-tolyl or 3,5-difluorobenzene; $\mathrm{R}^{\prime}=\mathrm{H}, \mathrm{CH}_{3}, 4$-tolyl). Heteroquaternary 2:2 complexes $(b$ and $c)$ in which the rigid diplatinum guest templated linear (trans dithiophene) or bent (cis dithiophene) conformations.

\subsection{2. homo-ditopic 2:2 complexes}

Toward symmetric 2:2 complexes. Li and co-workers recently reported the X-ray crystal structure of two $\mathrm{CB}$ [8] complexes of 2:2 stoichiometry (Figure 9). ${ }^{[61]}$ In the $1^{\text {st }}$ case, they observed an electron donor/acceptor assembly from the $\mathrm{CB}[8] \mathrm{co}$-inclusion of a $\mathrm{N}$-benzyl and a 4-phenylpyridinium group where the two cationic charges are distributed on each $\mathrm{CB}[8]$ carbonyl rim (Figure 9a). Conversely, the bis $(N$-methyl,4-phenylpyridinium) guest was arranged in the 2:2 complex via the bis(4-phenylpyridinium) coinclusion, so that showing twice, two cations facing one $\mathrm{CB}[8]$ carbonyl rim (Figure 9b). The cationic charge concentration on the same carbonyl rim was expected to be unfavorable, ${ }^{[44,62}$ eventually leading to the other $\mathrm{H}-\mathrm{T}$ arrangement and to supramolecular polymers. ${ }^{[63,64]}$ a) a)

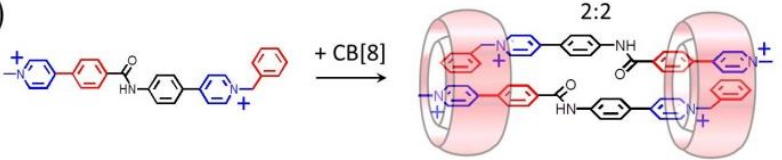

b)

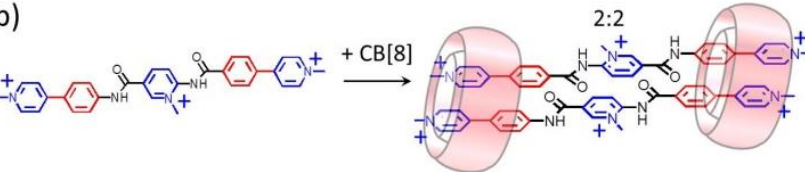

c)

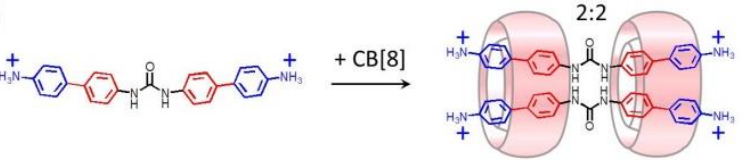

Figure 9. Three types of 2:2 complexes based on asymmetric guest molecules ( $\mathrm{a}$ and $\mathrm{b}$ ) and a bis-biphenylammonium-urea (c) with $\mathrm{CB}[8]$.

For homo-ditopic guests, the cationic charge distribution in $\mathrm{CB}[8]$ 2:2 complexes seems less important than the guest position in the cavity, ${ }^{[65]}$ and two cationic charges can face the same carbonyl rim. ${ }^{[6]}$ For instance, in 2008, Isaacs and coworkers studied diarylurea-diammoniums with $\mathrm{CB}[8]$, and observed host:guest 1:2 complexes but replacing two methylenes by two phenylenes afforded 2:2 complexes (Figure 9c). ${ }^{[67]}$ On the other hand, arylpyridinium groups, combining the $\mathrm{A}$ and $\mathrm{D}$ blocks in one flat guest, led to strong H-T 1:2 complexes, ${ }^{[68,69]}$ and corresponding dimers are excellent guests for the construction of $\mathrm{CB}[8]$-based $\mathrm{H}-\mathrm{H} \mathrm{2:2}$ complexes (Figure 2 and Figure 9b).

Transient 2:2 complexes. Recently, del Barrio, Scherman and coworkers prepared a bis( $N$-benzylpyridinium) homo-ditopic guest with an azo bond as a linker which formed 2:2 complexes with $\mathrm{CB}[8]$ in water (Figure 10). ${ }^{[70]}$

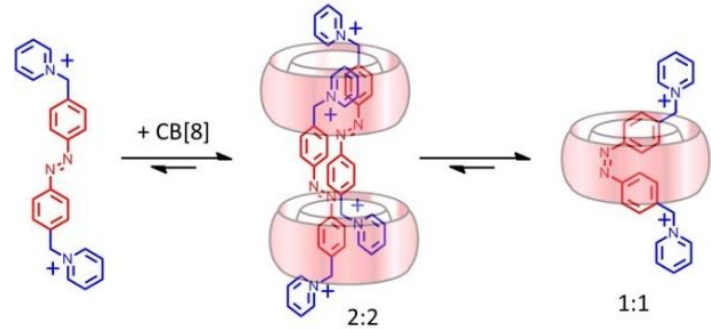

Figure 10. Transient formation of a $\mathrm{CB}[8]$-based 2:2 complex with a switchable, cationic azobenzene derivative. 
However, this complex was a kinetic product which evolved with time toward a 1:1 complex with simultaneous trans $\rightarrow$ cis isomerization of the azobenzene unit (Figure 10).

Symmetric 2:2 complexes of fluorescent dyes. While CB[7] and $\mathrm{CB}[8]$ usually bind on viologen stations when substituents are suitable, ${ }^{[14-18]}$ they can also bind aside on the grafted groups, singly for $\mathrm{CB}[7]$ or pairwise for $\mathrm{CB}[8]$ as for the examples of Figure 11. $\operatorname{Bis}(N$-aryl $)$ viologen guests have been shown to produce several 2:2 complexes with $\mathrm{CB}[8]$.

a)

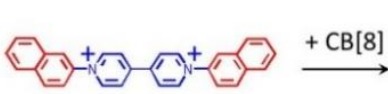

b)
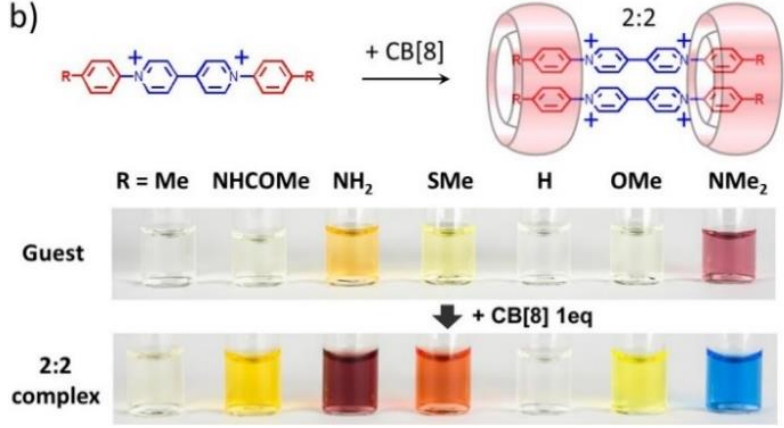

Figure 11..Diaryl-viologens can be relevant guests to form 2:2 complexes with $\mathrm{CB}[8]$ as shown by a bisnaphthyl-viologen (a) or bisphenyl-viologens (b) carrying various electron-donating groups. The complexation can be accompanied by dramatic color changes of guest aqueous solutions. Adapted from "G. Wu, M. Olesinska, Y. Wu, D. Matak-Vinkovic and O. A. Scherman, J. Am. Chem. Soc. 2017, 139, 3202" - Published by the American Chemical Society in open access [Creative Commons Attribution (CC-BY license)]

For example, Cao and co-workers prepared a bis $(N$ naphthalene)viologen affording, when mixed with $\mathrm{CB}[8]$, charge transfer 2:2 complexes with UV-vis absorption and fluorescence properties tuned by $\mathrm{CB}[7] / \mathrm{CB}[8]$ competitions (Figure 11a). ${ }^{[71]}$ In 2017, Scherman and co-workers found that $\mathrm{CB}[8]$ triggered 2:2 complex formation for diaryl-viologens with electron-donating groups (Figure 11b). ${ }^{[72]}$ Significant color changes were observed. In a following work, the synthesis of "extended" viologens was described with tolyl groups at the periphery, but with different aromatic groups at the center of the viologen (Figure 12). ${ }^{[73]}$

a)

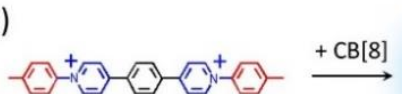

b)

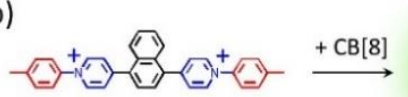

c)

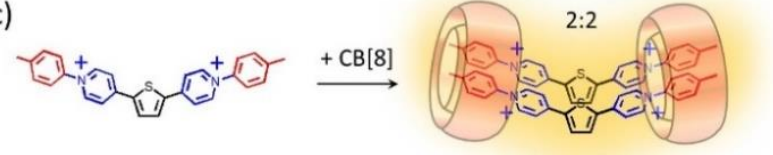

Figure 12. 2:2 complexes of "extended" viologens with $\mathrm{CB}[8]$. The central part of the guest was changed for tuning the photophysical properties of the guest.
Upon $\mathrm{CB}[8]$ addition in water, 2:2 complexes were observed, the luminescence of which could be tuned thanks to the chemical nature of the central part of the guest. While the phenyl and naphthyl complexes respectively show bright blue and green fluorescence, with rather high quantum yields and long fluorescence lifetimes, the thiophene analogue (Figure 12c) exhibited emission features typical of excimer-like structures. ${ }^{[73]}$ In a similar approach, Ma and co-workers have prepared a bis(4phenylpyridinium) guest with a triazine linker (Figure 13a).

a)

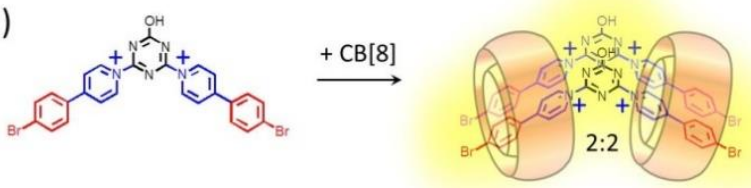

b) Daylight

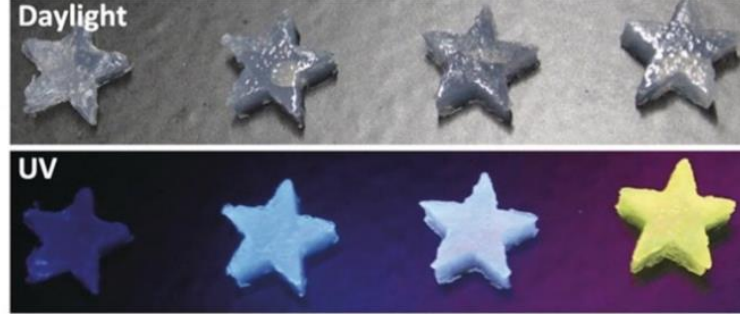

c)
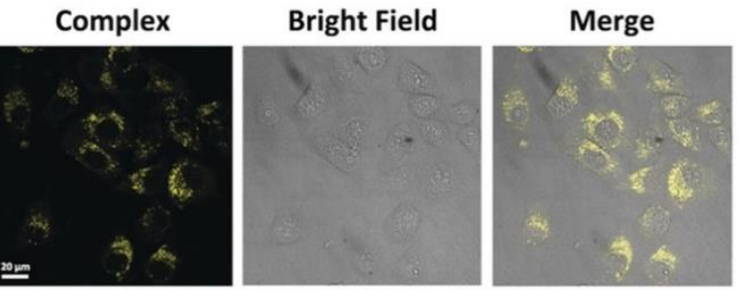

Figure 13. A bis-(aryl-pyridinium)-triazine guest forming an emitting $2: 2$ complex (a) with CB[8]. Phosphorescent properties are highlighted in panel (b) while fluorescence imaging in cells (c) was also reported. Adapted from " $J$. Wang, Z. Huang, X. Ma, H. Tian, Angew. Chem. Int. Ed., 2020, DOI: 10.1002/anie.201914513" - Published by Wiley.

The crystal structure showed a 2:2 complex with two arylpyridinium units bound by two $\mathrm{CB}[8]$ (Figure 13a). ${ }^{[7]}$ The restricted dynamics of the guests led to a host-stabilized charge transfer and a yellow emission was observed under visible light. This 2:2 complex is the $1^{\text {st }}$ phosphorescent organic compound excited by visible light at room-temperature in water. ${ }^{[74]}$ Phosphorescent hydrogels were prepared (Figure 13b) and the complex could also be used for fluorescence imaging of cells (Figure 13c). After initial findings on fluorescence modulation by 2:2 complex formation, ${ }^{[73]}$ Scherman and coworkers extended the concept by presenting a "clamp" strategy relying on the bimodal complexation of "clamping modules" by $\mathrm{CB}[8]$. This strategy allowed to find several types of 2:2 complexes (linear, curved and zig-zag, Figure 14). ${ }^{[75]}$ This way, fluorescent dimers could be studied more easily by avoiding time-consuming synthetic steps to get covalent dimers with precisely positioned fluorophores. Various guests including aryls, naphthyls, and anthracenyls cores linked to tolyl-pyridinium "clamping modules" were prepared (Figure 14) and the absorption and emission spectra of corresponding 2:2 complexes were investigated. For these 2:2 complexes, atypical excimer-like states are observed upon photoexcitation, with generally improved fluorescence lifetimes, and quantum yields either increased or decreased. 

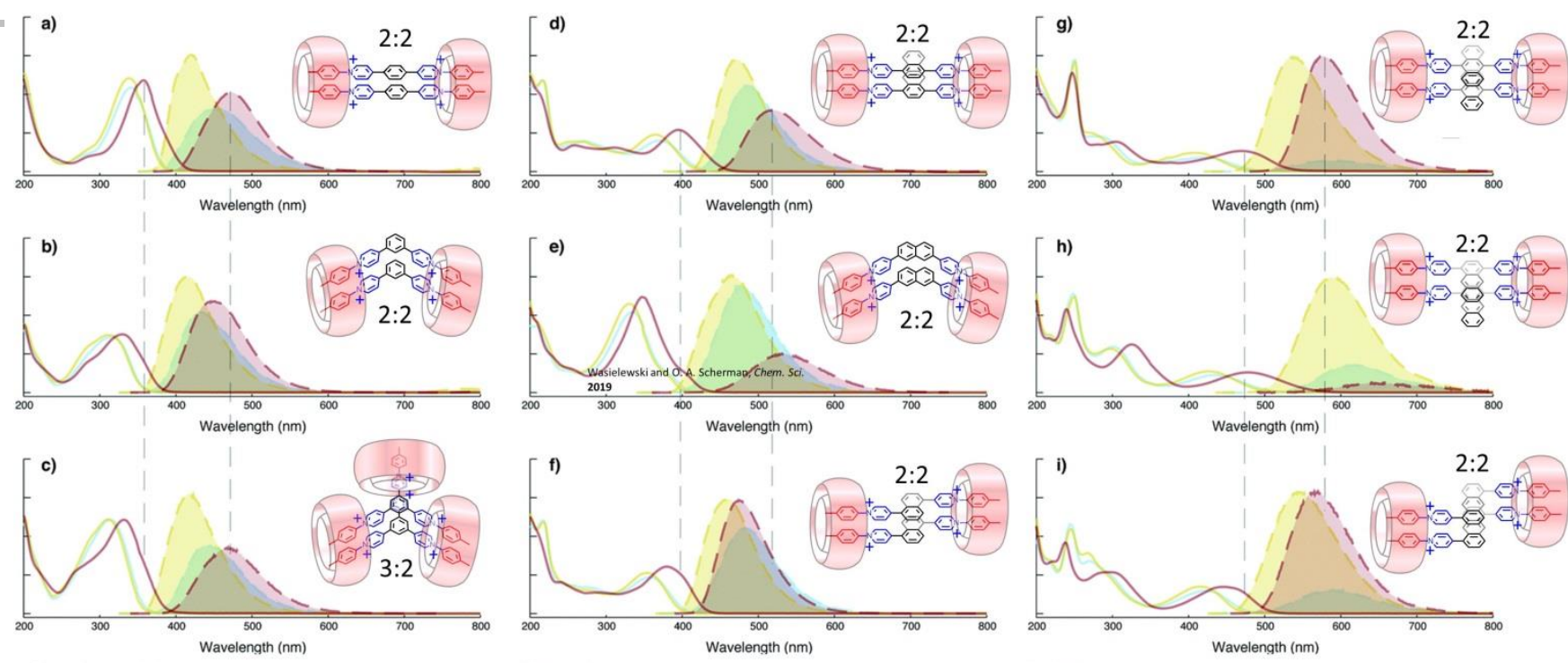

Clamping modules:
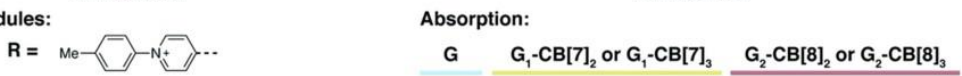

Emission:

G $\quad \mathrm{G}_{1}-\mathrm{CB}[7]_{2}$ or $\mathrm{G}_{1}-\mathrm{CB}[7]_{3} \quad \mathrm{G}_{2}-\mathrm{CB}[8]_{2}$ or $\mathrm{G}_{2}-\mathrm{CB}[8]_{3}$

Figure 14. Modular approach of constraining two fluorescent compounds by clamping the periphery of ditopic (two sites of binding) or tritopic (three sites of binding) guests by two or three $\mathrm{CB}[8]$. Absorption and emission spectra of the guests and corresponding 2:2 or 2:3 complexes are shown above highlighting the possible modulation of photophysical properties determined by the structure of the guest. Adapted from "G. Wu, Y. J. Bae, M. Olesińska, D. Antón-García, I. Szabó, E. Rosta, M. R. Wasielewski and O. A. Scherman, Chem. Sci., 2020, 11, 812" - Published by the Royal Society of Chemistry.

However, when the linker between the recognizing-blocks is long and flexible, supramolecular polymers were observed with $\mathrm{CB}[8]$, again illustrating the subtleties in guest design to control oligomer formation. ${ }^{766]}$

\subsubsection{General trends about 2:2 complexes}

More than 40 compounds have been reported to form $2: 2$ complexes with $\mathrm{CB}[8]$. While the absolute characterization of these complexes remains difficult, ${ }^{[77,}{ }^{78]}$ a panel of analytic methods is now available and their combination of several of them is often necessary to confirm the nature of the complex. While the most direct evidence (X-ray diffraction data) requires $\mathrm{X}$-ray quality single crystals, NMR and mass spectrometry have also become techniques of choice to probe host•guest stoichiometry. In particular, diffusion coefficients determined by DOSY NMR can allow estimating hydrodynamic radii, especially when the spherical approximation can be applied (Stokes-Einstein equation). ${ }^{[79]}$ Reported diffusion coefficients range from $1.58 \times 10$ ${ }^{10}$ to $2.24 \times 10^{-10} \mathrm{~m}^{2} \mathrm{~s}^{-1}$ (Table 1), presumably due to the various sizes and geometries of the assemblies in water. Additionally, estimates of the dynamic volume of 2:2 complexes can be done by ion mobility spectrometry (IMS) through measurements of collisional cross-sections. ${ }^{[72,80]}$ ITC, UV-Vis spectroscopy, light scattering techniques and molecular modelling usually complement the characterization.

As the host structure is always identical, the guest design is the key to get these peculiar assemblies, and a common feature of 2:2 complexes is rigidity. While several end-groups are now identified to favor 2:2 complex formation, rigid linkers appear important even though a few degrees of freedom are allowed. Flexible guests are more prone to afford unexpected assemblies or lead to dynamic equilibria between dimers, oligomers and polymers. For instance $\mathrm{Xu}$, Zhang and co-workers studied the $\mathrm{CB}[8]$ complexation of a bis(Brooker's merocyanine) guest bearing a flexible linker in $\mathrm{D}_{2} \mathrm{O}$ and observed the formation of oligomeric complexes. ${ }^{[81]}$ An elegant strategy to shift equilibria toward polymers is to use tetratopic (four sites of binding)

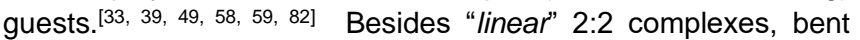
guests (Figures $8 \mathrm{c}, 12 \mathrm{c}, 13 \mathrm{a}, 14 \mathrm{~b}$ or $14 \mathrm{e}),{ }^{[60,73-75]}$ lead to rigid but "curved" 2:2 complexes which could be useful for the construction of more advanced architectures. This raises the question of the absence of cyclic $n: n$ oligomers, when $C B[8]$ is mixed with guests having a $\theta$ angle between building-blocks different from $180^{\circ}$ (Figure 2).

In fact, a few guests trigger formation of such assemblies with $\mathrm{CB}[8]$ (cyclic 4:4, 5:5 and 6:6 oligomers, vide supra). In these cases, the $\theta$ angle of the guest nicely match those in the final complex, suggesting that preorganizing recognizing-blocks with the right angles in a guest could enhance chances to get higher order assemblies.

In principle, considering the cyclic $\mathrm{n}: \mathrm{n}$ complexes as planar polygons, their construction could follow targeted geometric shapes, with $\mathrm{CB}[8]$ co-inclusion generating the polygon sides and the $\theta$ angle of the guest linker controlling the final size ( $n$ value) of the supramolecular polygon. ${ }^{[83,84]}$

Up to now, square $2: 2$ and triangular $3: 3$ oligomers are not reported using this strategy, like $n: n$ oligomers with $n>6$ (Figure 1). Finally, introduction of relevant groups on the guest has imparted new properties for these assemblies. Aza-type recognizing blocks in ditopic guests allowed modulating the stoichiometry of $\mathrm{CB}[8]$ complexes, ${ }^{[58,59,70]}$ that have also showed new properties, specific of the $n: n$ arrangements such as conformational control, ${ }^{600]}$ fluorescence contro|[51, 53,55,71,73,75] or unusual $\mathrm{p} K_{\mathrm{a}}$ shift. ${ }^{[56]}$ Finally, a hybrid covalent:non-covalent approach with a functionalized $\mathrm{CB}[6]$ afforded daisy-chain dimers featuring two cavities and two guest fragments. ${ }^{[85]}$ 
Table 1. Structures of 2:2 complexes and corresponding values of diffusion coefficients $(D)$ measured by DOSY at room temperature.

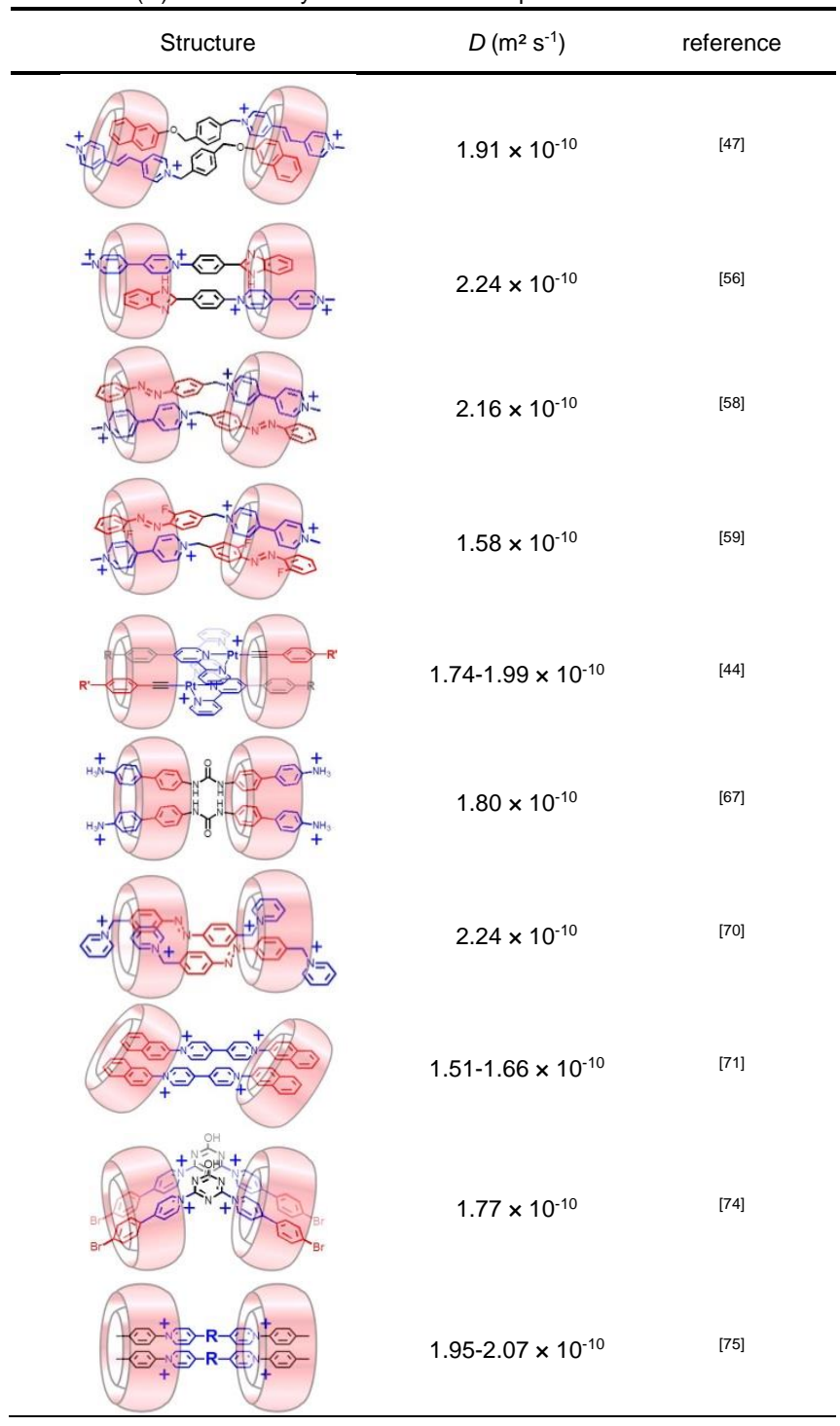

\section{3- 3:3 complexes. Triangular assemblies.}

While 1:1 host•guest complexes are largely documented, it is strange to note that their spontaneous organization in more complex architectures remains rare. In 2009, three teams independently reported the formation of $3: 3 \mathrm{CB}[8] \cdot$ guest structures $^{[66-88]}$ where the guest is a paramagnetic TEMPO-type nitroxide (Figure 15) ${ }^{[89]}$ In these cases, the guests are monotopic and are only bound once in each $\mathrm{CB}[8]$. Recently, a diamagnetic guest was also shown to trigger triangular 3:3 assembly favoured by $\mathrm{Na}^{+}$or $\mathrm{K}^{+}$cations as found by DLS and DOSY. ${ }^{[34]}$ The tendency of $\mathrm{CB}[8]$ to self-associate in water was combined with directional interactions between the guests and the hosts to explain the formation of $\mathrm{CB}[8]$ triangles, the center of which provides an environment mimicking that of oxygen-rich molecular cryptands, suitable for alkali metal cations of small size. Equilibria between 1:1 and 3:3 complexes were observed with exceptions detected in the gas phase ${ }^{[34,43]}$ or solid phase. ${ }^{[86]}$ a)

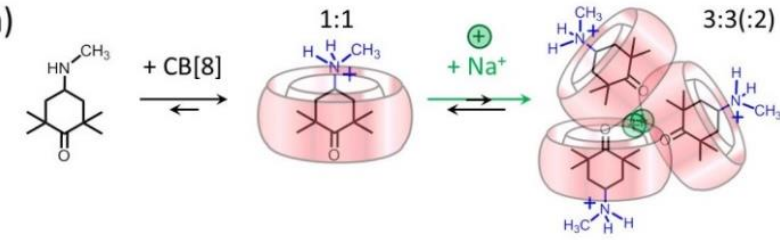

b)

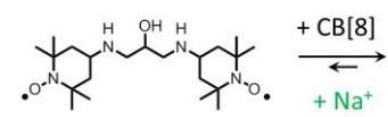

$\oplus$

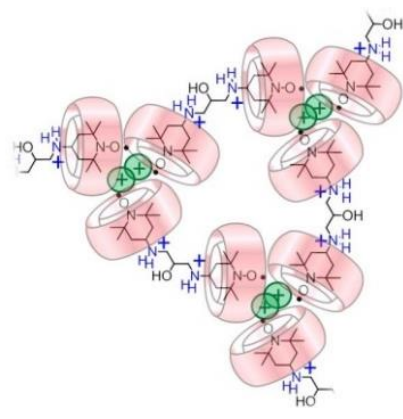

Figure 15. Example of a $1: 1 \rightarrow 3: 3$ equilibrium (a), shifted to the triangular assembly with $\mathrm{Na}^{+}$cations and reticulation (b) by a ditopic guest. ${ }^{[34]}$

Other guests may be able to trigger $4: 4$ host guest squares or other $\mathrm{n}: \mathrm{n}$ oligomers in solution in the future. As a particular case due to the size of its cavity, $\mathrm{CB}[10]$ could in principle be used to get linear 3:3 assemblies with appropriate guests. Finally, with the right ditopic guest, cucurbituril and metal ion, the groups of Kim ${ }^{[90]}$ and Isaacs ${ }^{[91]}$ could isolate triangular $3: 3: 3$ or square $4: 4: 4$ molecular necklaces (Figure 16). ${ }^{[92]}$
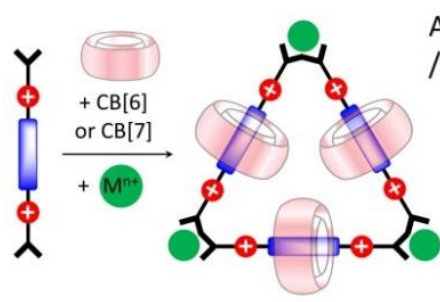

$3: 3: 3$

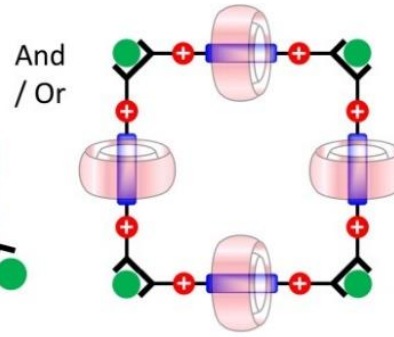

$4: 4: 4$
Figure 16. A general approach to get triangular or square molecular necklaces using $\mathrm{CBs}$, the right guests and metal ions.

\section{4- 4:4 complexes. Square assemblies.}

In 2009, a square 4:4 CB[7]•radical oligomer was reported in the solid state (Figure 17) although not stable in water. ${ }^{[86]}$ This is a rare case of a $\mathrm{CB}$ [7] based oligomeric assembly with oriented guests. The $\mathrm{CB}[7]$ hosts are arranged similar to the general packing of cucurbiturils in the solid state,${ }^{[93,94]}$ that is following a tendency to close their cavities with nearest neighbors placed almost orthogonally.
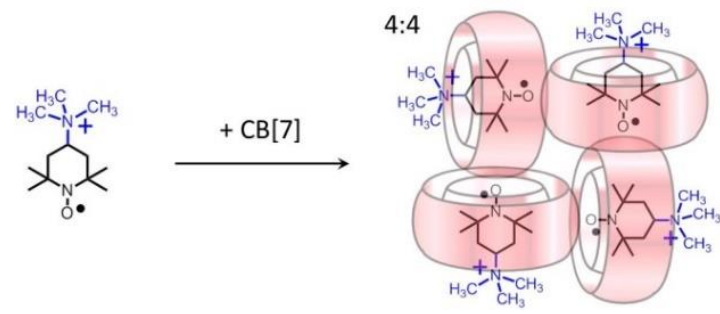

Figure 17. Scheme of the $4: 4 \mathrm{CB}[7] \cdot$ nitroxide oligomer. 
In 2016, another square-shape 4:4 complex was described comprising four $\mathrm{CB}[8]$ and four guests presenting two recognition units that are about $90^{\circ}$ related (Figure 18). ${ }^{[95]}$
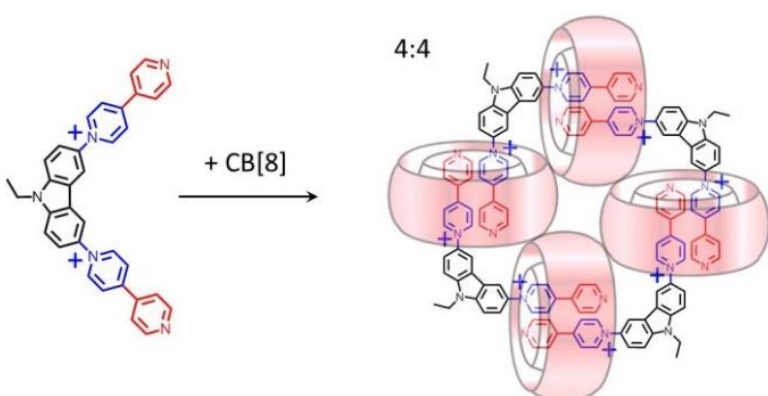

Figure 18. A square $4: 4$ complex of $\mathrm{CB}[8]$ with a dipyridinium-carbazole guest.

Double recognition of the pyridine-pyridinium units by $\mathrm{CB}[8]$ combined by the rigid guest structure featuring a $\theta$ angle of $\approx 90^{\circ}$ on the carbazole core, directed the system to a single outcome as found by DOSY and modelling. ${ }^{[71,95]}$ The $\mathrm{pH}$ responsive pyridine groups enabled to switch the assembly to $1: 1$ complexes at relevant $\mathrm{pH}$. Another strategy leading to pseudo-4:4 complexes consisted to graft an alkyl chain bearing an ammonium group on $\mathrm{CB}[7]$ (Figure 19). ${ }^{\left[{ }^{[6]}\right.}$ The diffusion coefficient is close to that of the non-covalent 4:4 assembly ${ }^{[95]}$ and MS also supports the occurrence of a single oligomer.

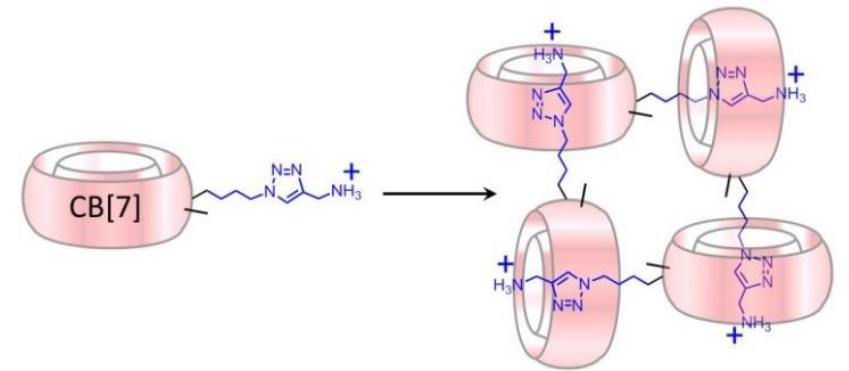

Figure 19. Example of a tetramer of a $\mathrm{CB}$ [7] derivative regarded as a covalent analogue of the $4: 4$ assemblies.

\section{5- 5:5 complex. A pentagon assembly.}

Kim and co-workers reported in 2004 a rare example of a supramolecular analogue of a [6]-molecular necklace featuring 5 $\mathrm{CB}[8]$ and 5 guests having a naphthalene and a dicationic dipyridyliumylethylene (Figure 20). ${ }^{[48]}$

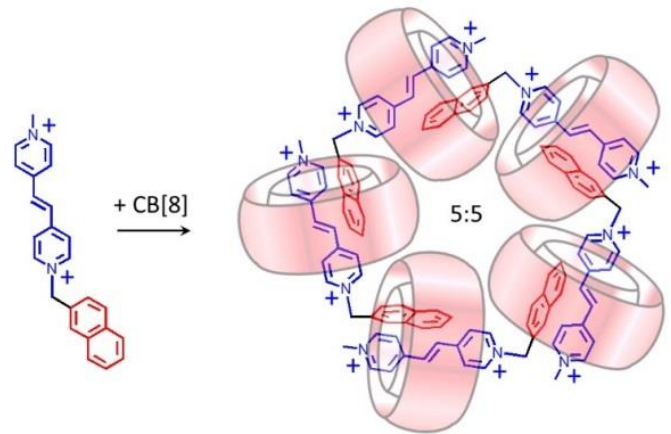

Figure 20. A 5:5 complex of $\mathrm{CB}[8]$ and a naphthalene-dipyridyliumylethylene guest.
It is striking to note that the guest design is not that different from those of Figure 3. Yet, 5:5 complexes were observed, presumably because the angle between the guest subunits is not too different from those in a pentagon and the steric hindrance is compatible with this assembly. DOSY afforded aligned signals for the guest and the host suggesting a hydrodynamic volume about 9 times that of $\mathrm{CB}[8]$ hence supporting the proposed 5:5 arrangement which was confirmed by NOESY, mass spectrometry, modelling and X-ray diffraction. Although not perfect, the solid-state structure clearly showed the pentameric structure and other oligomers are unlikely due to (i) the sharpness of the DOSY signals and (ii) the higher energy strain for the cyclic tetramer or hexamer. This example illustrates well the subtleties in guest design for targeting $n: n$ oligomers of precise size and shape.

\section{6- 6:6 complex. A hexagon assembly.}

In 2013, Zhao, Liu, Li and co-workers used the double-recognition of the pyridine-pyridinium motif to build a series of host•guest assemblies from 2:2 complexes to honeycomb, single layer $2 \mathrm{D}$ polymers. ${ }^{[97]}$ One of the structures was a 6:6 complex with six $\mathrm{CB}[8]$ and six appropriate rigid guests with $\theta=120^{\circ}$ between subunits. However, residues on the central core also played a critical role since only one residue type ( $R$ groups on Figure 21 ) afforded the 6:6 complexes ${ }^{[97]}$ while other groups afforded smaller 2:2 complexes.


Figure 21. A 6:6 complex based on $\mathrm{CB}[8]$ co-sequestration of pyridinepyridinium blocks, $120^{\circ}$ related by a central 1,3-triphenylene core.

Other oligomers are unlikely due to the good match of size determined by DLS and DOSY and corresponding to a $6: 6$ complex. The occurrence of a single cyclic oligomer for the relevant $R$ group is puzzling, especially in a context of possible competitive supramolecular polymerization and 2:2 complex formation. One parameter that could discriminate between 2:2 and 6:6 complexes is steric hindrance around the central core. While this is expected to be increased in 2:2 complexes, 6:6 complexes may offer the possibility of $\mathrm{CB}[8]$ binding without this constrain. The 6:6 complex can be seen as a small growing polymer which closed on itself, possibly due to entropic effects. ${ }^{[98]}$ The parallel with the mechanism of cucurbituril covalent synthesis is striking. For $\mathrm{CB}$ synthesis, it has been shown that growing 
oligomers prefer adopting a C-shape geometry eventually favoring the closure. ${ }^{99,}$, 100] This type of bias (an angle between glycoluril units) could be paralleled with the defined $\theta$ angle of Figure 2, suggested to direct the successive self-assembly events to a self-closure of the growing $n: n$ oligomer.

\section{7- $n: n$ linear and cyclic oligomers of large size}

In 2014, ${ }^{[101]}$ Masson and coworkers discovered that linear homooligomers of various length could be formed by mixing $\mathrm{Fe}$ complexes or Ir complexes with $\mathrm{CB}[8]$. By mixing the two metal complexes with $\mathrm{CB}[8]$, hetero-oligomers were observed with an alternated sequence of $\mathrm{Fe}$ and Ir complexes suggesting social self-sorting. This work was extended in $2018^{[102]}$ with different complexes of $\mathrm{Fe}$ and Ir affording again linear homo-oligomers and hetero-oligomers characterized by a repetitive sequence of Fe-IrIr complexes. These oligomers could also be considered as oligo(2:2) and oligo-(3:3) complexes respectively. In another frontier system, Urbach and coworkers have described partially covalent analogues of a 2:4 and a 3:6 host:guest system that can be seen as cyclic $2: 2$ and bicyclic 3:2 complexes respectively. ${ }^{[103]}$ Using the double recognition of phenylalanine by $\mathrm{CB}[8],{ }^{[27]} \mathrm{Liu}$ and colleagues designed doubly FGG-tagged proteins that were circularly oligomerized thanks to $\mathrm{CB}[8] .{ }^{[98]}$ However these $n: n$ $\mathrm{CB}[8] \cdot$ protein oligomers were not monodisperse and the number of building-blocks was not discussed. Yet, this "hybrid" example, at the interface of chemistry and biology, shows the relevance of using $\mathrm{CBs}^{[78,94,104]}$ for the design and preparation of new $\mathrm{n}: \mathrm{n}$ oligomers of very large size with biological relevance.

\section{3- Conclusions and Outlook}

CB based host guest complexes of precise shape having as many hosts as they have guests, have started to attract attention. While the vast majority of examples are 2:2 complexes, improved control over these assemblies suggests that numerous analogues will be accessed in the future, expanding possibilities in terms of size, shape, and function. This form of control of supramolecular aggregation could be very useful in the future, allowing to skip, often time-consuming synthetic and purification steps for covalent dimers, trimers or oligomers of controlled size. For this burgeoning field, cucurbiturils are excellent building-blocks featuring high binding constants with reliable ternary complex formation, relevant for supramolecular linking of guest subunits in water. However, multiple or competitive binding can bias equilibria to unwanted outcomes and guest design must be wellthought. In this vein, anticipate an oligomer size after $C B[8]$ addition, solely based on the guest structure remains challenging. For this reason, theoretical (predictive) approaches based on modelling could be helpful to fine-tune a guest structure and design a precise oligomeric architecture. Alternatively, the motifs shown on Figure 2 could tentatively be applied to target oligomeric cucurbituril complexes. Furthermore, tritopic ${ }^{[97,105]}$ and tetratopic ${ }^{[106]}$ guests could also expand the structural space of oligomers assembled with $\mathrm{CB}$ [8]. Until now, planar tritopic guests have mainly been studied, leading to honeycomb $2 \mathrm{D}$ polymers or large 3D nanocapsules, ${ }^{[107]}$ but multitopic guests with a controlled 3D structure could afford more sophisticated objects. Beyond applications mentioned in this review, catalysis has not yet been explored in this context. Likewise, FRET or template synthesis could greatly benefit from this $\mathrm{CB}$ based oligomerization by synergistic effects, specific to the oligomers. To conclude, the nearly exclusive solvent for these assemblies is water, opening interesting perspectives in biology. Indeed, larger oligomers such as 7:7, 8:8 or 9:9 nanorings could be key components of future applications, reminding the shape of the circularly assembled proteins briefly mentioned in the introduction and performing fascinating tasks in cells.

\section{Acknowledgements}

CNRS and Aix Marseille Université are acknowledged for continuous support. This work was also partly funded by University of Macau (MYRG2019-00059-ICMS) and National Science Foundation of China (21871301). In addition, DB is also financially supported by UM Macao Distinguished Visiting Scholar Program.

Keywords: Host:Guest • n:n complexes • Cucurbituril • oligomers $\cdot$ supramolecular

\section{References}

[1] F. Chiti, C. M. Dobson, Annu. Rev. Biochem. 2006, 75, 333-366.

[2] C. Haass, D. J. Selkoe, Nat. Rev. Mol. Cell Biol. 2007, 8, 101-112.

[3] M. Gross, Curr. Biol. 2012, 22, R175-R177.

[4] J. A. Lukin, C. Ho, Chem. Rev. 2004, 104, 1219-1230.

[5] Y. Yuan, M. F. Tam, V. Simplaceanu, C. Ho, Chem. Rev. 2015, 115, $1702-1724$.

[6] J. B. Rafferty, S. E. Sedelnikova, D. Hargreaves, P. J. Artymiuk, P. J. Baker, G. J. Sharples, A. A. Mahdi, R. G. Lloyd, D. W. Rice, Science 1996, 274, 415-421.

[7] R. H. P. Law, N. Lukoyanova, I. Voskoboinik, T. T. Caradoc-Davies, K. Baran, M. A. Dunstone, M. E. D'Angelo, E. V. Orlova, F. Coulibaly, S. Verschoor, K. A. Browne, A. Ciccone, M. J. Kuiper, P. I. Bird, J. A Trapani, H. R. Saibil, J. C. Whisstock, Nature 2010, 468, 447-451.

[8] S. S. Pang, C. Bayly-Jones, M. Radjainia, B. A. Spicer, R. H. P. Law, A. W. Hodel, E. S. Parsons, S. M. Ekkel, P. J. Conroy, G. Ramm, H. Venugopal, P. I. Bird, B. W. Hoogenboom, I. Voskoboinik, Y. Gambin, E. Sierecki, M. A. Dunstone, J. C. Whisstock, Nat. Commun. 2019, 10, 4288.

[9] K. a. Brejc, W. J. van Dijk, R. V. Klaassen, M. Schuurmans, J. van der Oost, A. B. Smit, T. K. Sixma, Nature 2001, 411, 269-276.

[10] N. Unwin, J. Mol. Biol. 2005, 346, 967-989.

[11] W. Liu, S. K. Samanta, B. D. Smith, L. Isaacs, Chem. Soc. Rev. 2017, 46, 2391-2403.

[12] L. R. MacGillivray, J. L. Atwood, Nature 1997, 389, 469-472.

[13] D. Fujita, Y. Ueda, S. Sato, N. Mizuno, T. Kumasaka, M. Fujita, Nature 2016, 540, 563-566.

[14] J. W. Lee, S. Samal, N. Selvapalam, H.-J. Kim, K. Kim, Acc. Chem. Res. 2003, 36, 621-630.

[15] J. Lagona, P. Mukhopadhyay, S. Chakrabarti, L. Isaacs, Angew. Chem., Int. Ed. 2005, 44, 4844-4870.

[16] E. Masson, X. Ling, R. Joseph, L. Kyeremeh-Mensah, X. Lu, RSC Adv. 2012, 2, 1213-1247.

[17] S. J. Barrow, S. Kasera, M. J. Rowland, J. del Barrio, O. A. Scherman, Chem. Rev. 2015, 115, 12320-12406.

[18] K. I. Assaf, W. M. Nau, Chem. Soc. Rev. 2015, 44, 394-418.

[19] J. Szejtli, Chem. Rev. 1998, 98, 1743-1753.

[20] A. Ikeda, S. Shinkai, Chem. Rev. 1997, 97, 1713-1734. 
[21] E. Pazos, P. Novo, C. Peinador, A. E. Kaifer, M. D. García, Angew. Chem., Int. Ed. 2019, 58, 403-416.

[22] L. Isaacs, Acc. Chem. Res. 2014, 47, 2052-2062.

[23] F. Biedermann, V. D. Uzunova, O. A. Scherman, W. M. Nau, A. De Simone, J. Am. Chem. Soc. 2012, 134, 15318-15323.

[24] L. Cao, M. Sekutor, P. Y. Zavalij, K. Mlinaric-Majerski, R. Glaser, L. Isaacs, Angew. Chem., Int. Ed. 2014, 53, 988-993.

[25] H.-J. Kim, J. Heo, W. S. Jeon, E. Lee, J. Kim, S. Sakamoto, K. Yamaguchi, K. Kim, Angew. Chem., Int. Ed. 2001, 40, 1526-1529.

[26] Y. H. Ko, E. Kim, I. Hwang, K. Kim, Chem. Commun. 2007, 1305-1315.

[27] L. M. Heitmann, A. B. Taylor, P. J. Hart, A. R. Urbach, J. Am. Chem. Soc. 2006, 128, 12574-12581.

[28] H. D. Nguyen, D. T. Dang, J. L. J. van Dongen, L. Brunsveld, Angew. Chem., Int. Ed. 2010, 49, 895-898.

[29] W. Wang, A. E. Kaifer, Angew. Chem., Int. Ed. 2006, 45, 7042-7046.

[30] J. W. Lee, S. C. Hain, J. H. Kim, Y. H. Ko, K. Kim, Bull. Korean Chem. Soc. 2007, 28, 1837-1840.

[31] U. Rauwald, O. A. Scherman, Angew. Chem., Int. Ed. 2008, 47, 39503953.

[32] Y. Liu, H. Yang, Z. Wang, X. Zhang, Chem. - Asian J. 2013, 8, 16261632.

[33] H. D. Correia, S. Chowdhury, A. P. Ramos, L. Guy, G. J.-F. Demets, C. Bucher, Polym. Int. 2019, 64, 572-588.

[34] S. Combes, K. T. Tran, M. M. Ayhan, H. Karoui, A. Rockenbauer, A. Tonetto, V. Monnier, L. Charles, R. Rosas, S. Viel, D. Siri, P. Tordo, S. Clair, R. Wang, D. Bardelang, O. Ouari, J. Am. Chem. Soc. 2019, 141, 5897-5907.

[35] F. Guagnini, P. M. Antonik, M. L. Rennie, P. O'Byrne, A. R. Khan, R. Pinalli, E. Dalcanale, P. B. Crowley, Angew. Chem., Int. Ed. 2018, 57, 7126-7130.

[36] J. Lu, J.-X. Lin, M.-N. Cao, R. Cao, Coord. Chem. Rev. 2013, 257, 13341356.

[37] J.-F. Dufourd, Theor. Comput. Sci. 2008, 403, 133-159.

[38] L. Yang, X. Tan, Z. Wang, X. Zhang, Chem. Rev. 2015, 115, 7196-7239.

[39] H. Zou, J. Liu, Y. Li, X. Li, X. Wang, Small 2018, 14, 1802234.

[40] Y.-L. Liu, K. Liu, Z.-Q. Wang, X. Zhang, Chem. - Eur. J. 2011, 17, 99309935.

[41] Y. Liu, Z. Huang, X. Tan, Z. Wang, X. Zhang, Chem. Commun. 2013, 49, 5766-5768.

[42] X. Shi, X. Zhang, X.-L. Ni, H. Zhang, P. Wei, J. Liu, H. Xing, H.-Q. Peng, J. W. Y. Lam, P. Zhang, Z. Wang, H. Hao, B. Z. Tang, Macromolecules 2019, 52, 8814-8825.

[43] J. P. Da Silva, N. Jayaraj, S. Jockusch, N. J. Turro, V. Ramamurthy, Org. Lett. 2011, 13, 2410-2413.

[44] K. Kotturi, E. Masson, Chem. Eur. J. 2018, 24, 8670-8678.

[45] J. W. Lee, K. Kim, S. Choi, Y. H. Ko, S. Sakamoto, K. Yamaguchi, K. Kim, Chem. Commun. 2002, 2692-2693.

[46] K. Kim, D. Kim, J. W. Lee, Y. H. Ko, K. Kim, Chem. Commun. 2004, 848849.

[47] Y. H. Ko, K. Kim, E. Kim, K. Kim, Supramol. Chem. 2007, 19, 287-293.

[48] Y. H. Ko, K. Kim, J.-K. Kang, H. Chun, J. W. Lee, S. Sakamoto, K. Yamaguchi, J. C. Fettinger, K. Kim, J. Am. Chem. Soc. 2004, 126, 1932 1933.

[49] Y. Liu, Y. Yu, J. Gao, Z. Wang, X. Zhang, Angew. Chem., Int. Ed. 2010 49, 6576-6579.

[50] K. Madasamy, D. Velayutham, M. Kathiresan, ACS Omega 2019, 4, 8528-8538.

[51] J. Mohanty, S. D. Choudhury, H. P. Upadhyaya, A. C. Bhasikuttan, H. Pal, Chem. - Eur. J. 2009, 15, 5215-5219.

[52] H. LeVine, III, Protein Sci. 1993, 2, 404-410.

[53] J. Mohanty, N. Thakur, S. Dutta Choudhury, N. Barooah, H. Pal, A. C. Bhasikuttan, J. Phys. Chem. B 2012, 116, 130-135.

[54] Y. Xu, M. Guo, X. Li, A. Malkovskiy, C. Wesdemiotis, Y. Pang, Chem. Commun. 2011, 47, 8883-8885.

[55] S. Schoder, H. V. Schröder, L. Cera, R. Puttreddy, A. Güttler, U. ReschGenger, K. Rissanen, C. A. Schalley, Chem. - Eur. J. 2019, 25, 3257 3261.
[56] H. Yin, Q. Cheng, R. Rosas, S. Viel, V. Monnier, L. Charles, D. Siri, D. Gigmes, O. Ouari, R. Wang, A. Kermagoret, D. Bardelang, Chem. - Eur. J. 2019, 25, 12552-12559.

[57] Q. Cheng, H. Yin, R. Rosas, D. Gigmes, O. Ouari, R. Wang, A. Kermagoret, D. Bardelang, Chem. Commun. 2018, 54, 13825-13828.

[58] J. del Barrio, P. N. Horton, D. Lairez, G. O. Lloyd, C. Toprakcioglu, O. A. Scherman, J. Am. Chem. Soc. 2013, 135, 11760-11763.

[59] T.-T. Jin, X.-H. Zhou, Y.-F. Yin, T.-G. Zhan, J. Cui, L.-J. Liu, L.-C. Kong, K.-D. Zhang, Chem. - Asian J. 2018, 13, 2818-2823.

[60] N. A. Thompson, H. Barbero, E. Masson, Chem. Commun. 2019, 55, 12160-12163.

[61] B. Yang, S.-B. Yu, H. Wang, D.-W. Zhang, Z.-T. Li, Chem. - Asian J. 2018, 13, 1312-1317.

[62] S. Senler, L. Cui, A. M. Broomes, E. L. Smith, J. N. Wilson, A. E. Kaifer, J. Phys. Org. Chem. 2012, 25, 592-596.

[63] F. Lin, T.-G. Zhan, T.-Y. Zhou, K.-D. Zhang, G.-Y. Li, J. Wu, X. Zhao Chem. Commun. 2014, 50, 7982-7985.

[64] M.-H. Xiang, Q.-Y. Qi, X. Zheng, X. Zhao, Tetrahedron Lett. 2019, 60, 1727-1731.

[65] S.-H. Li, X. Xu, Y. Zhou, Q. Zhao, Y. Liu, Org. Lett. 2017, 19, 6650-6653

[66] S. Y. Jon, Y. H. Ko, S. H. Park, H.-J. Kim, K. Kim, Chem. Commun. 2001, 1938-1939.

[67] S. Chakrabarti, L. Isaacs, Supramol. Chem. 2008, 20, 191-199.

[68] G. A. Vincil, A. R. Urbach, Supramol. Chem. 2008, 20, 681-687.

[69] Y. Zhang, T.-Y. Zhou, K.-D. Zhang, J.-L. Dai, Y.-Y. Zhu, X. Zhao, Chem. - Asian J. 2014, 9, 1530-1534.

[70] J. del Barrio, S. T. J. Ryan, P. G. Jambrina, E. Rosta, O. A. Scherman, J. Am. Chem. Soc. 2016, 138, 5745-5748.

[71] B. Zhang, Y. Dong, J. Li, Y. Yu, C. Li, L. Cao, Chin. J. Chem. 2019, 37, 269-275.

[72] G. Wu, M. Olesińska, Y. Wu, D. Matak-Vinkovic, O. A. Scherman, J. Am. Chem. Soc. 2017, 139, 3202-3208.

[73] M. Olesińska, G. Wu, S. Gómez-Coca, D. Antón-García, I. Szabó, E. Rosta, O. A. Scherman, Chem. Sci. 2019, 10, 8806-8811.

[74] J. Wang, Z. Huang, X. Ma, H. Tian, Angew Chem Int Ed Engl 2019, doi.org/10.1002/anie.201914513

[75] G. Wu, Y. J. Bae, M. Olesińska, D. Antón-García, I. Szabó, E. Rosta, M. R. Wasielewski, O. A. Scherman, Chem. Sci. 2020, 11, 812-825.

[76] T. Qian, F. Chen, Y. Chen, Y.-X. Wang, W. Hu, Chem. Commun. 2017, 53, 11822-11825.

[77] G. Wu, D. E. Clarke, C. Wu, O. A. Scherman, Org. Biomol. Chem. 2019, 17, 3514-3520.

[78] M. Ramaekers, S. P. W. Wijnands, J. L. J. van Dongen, L. Brunsveld, P. Y. W. Dankers, Chem. Commun. 2015, 51, 3147-3150.

[79] L. Avram, Y. Cohen, Chem. Soc. Rev. 2015, 44, 586-602.

[80] J. W. Lee, K. L. Davidson, M. F. Bush, H. I. Kim, Analyst 2017, 142, 4289 4298.

[81] Y. Kang, Z. Cai, Z. Huang, X. Tang, J.-F. Xu, X. Zhang, ACS Macro Lett. 2016, 5, 1397-1401.

[82] L. Yang, Y. Bai, X. Tan, Z. Wang, X. Zhang, ACS Macro Lett. 2015, 4, 611-615.

[83] S. Zhang, L. Zhao, Acc. Chem. Res. 2018, 51, 2535-2545.

[84] L. Zhao, B. H. Northrop, P. J. Stang, J. Am. Chem. Soc. 2008, 130, $11886-11888$

[85] L. Cao, L. Isaacs, Org. Lett. 2012, 14, 3072-3075.

[86] N. Jayaraj, M. Porel, M. F. Ottaviani, M. V. S. N. Maddipatla, A. Modelli, J. P. Da Silva, B. R. Bhogala, B. Captain, S. Jockusch, N. J. Turro, V. Ramamurthy, Langmuir 2009, 25, 13820-13832.

[87] D. Bardelang, K. Banaszak, H. Karoui, A. Rockenbauer, M. Waite, K. Udachin, J. A. Ripmeester, C. I. Ratcliffe, O. Ouari, P. Tordo, J. Am. Chem. Soc. 2009, 131, 5402-5404.

[88] E. Mileo, E. Mezzina, F. Grepioni, G. F. Pedulli, M. Lucarini, Chem. - Eur. J. 2009, 15, 7859-7862.

[89] O. Ouari, D. Bardelang, Isr. J. Chem. 2018, 58, 343-356

[90] K.-M. Park, S.-Y. Kim, J. Heo, D. Whang, S. Sakamoto, K. Yamaguchi, K. Kim, J. Am. Chem. Soc. 2002, 124, 2140-2147. 
[91] S. K. Samanta, K. G. Brady, L. Isaacs, Chem. Commun. 2017, 53, $2756-$ 2759.

[92] K. Kim, Chem. Soc. Rev. 2002, 31, 96-107.

[93] D. Bardelang, K. A. Udachin, D. M. Leek, J. C. Margeson, G. Chan, C. I. Ratcliffe, J. A. Ripmeester, Cryst. Growth Des. 2011, 11, 5598-5614.

[94] F. Guagnini, S. Engilberge, K. O. Ramberg, J. Pérez, P. B. Crowley, Chem. Commun. 2020, 56, 360-363.

[95] J. Li, Y. Yu, L. Luo, Y. Li, P. Wang, L. Cao, B. Wu, Tetrahedron Lett. 2016, 57, 2306-2310.

[96] B. Vinciguerra, L. Cao, J. R. Cannon, P. Y. Zavalij, C. Fenselau, L. Isaacs, J. Am. Chem. Soc. 2012, 134, 13133-13140.

[97] K.-D. Zhang, J. Tian, D. Hanifi, Y. Zhang, A. C.-H. Sue, T.-Y. Zhou, L. Zhang, X. Zhao, Y. Liu, Z.-T. Li, J. Am. Chem. Soc. 2013, 135, 1791317918.

[98] X. Li, Y. Bai, Z. Huang, C. Si, Z. Dong, Q. Luo, J. Liu, Nanoscale 2017, 9, 7991-7997.

[99] A. Day, A. P. Arnold, R. J. Blanch, B. Snushall, J. Org. Chem. 2001, 66, 8094-8100.

[100] W.-H. Huang, P. Y. Zavalij, L. Isaacs, J. Am. Chem. Soc. 2008, 130, 8446-8454.

[101] R. Joseph, A. Nkrumah, R. J. Clark, E. Masson, J. Am. Chem. Soc. 2014, 136, 6602-6607.

[102] M. Raeisi, K. Kotturi, I. del Valle, J. Schulz, P. Dornblut, E. Masson, J. Am. Chem. Soc. 2018, 140, 3371-3377.

[103] J. J. Reczek, A. A. Kennedy, B. T. Halbert, A. R. Urbach, J. Am. Chem. Soc. 2009, 131, 2408-2415.

[104] P. J. de Vink, J. M. Briels, T. Schrader, L.-G. Milroy, L. Brunsveld, C. Ottmann, Angew. Chem., Int. Ed. 2017, 56, 8998-9002.

[105] L. Zhang, T.-Y. Zhou, J. Tian, H. Wang, D.-W. Zhang, X. Zhao, Y. Liu, Z.-T. Li, Polym. Chem. 2014, 5, 4715-4721.

[106] S. Chowdhury, Y. Nassar, L. Guy, D. Frath, F. Chevallier, E. Dumont, A. P. Ramos, G. J.-F. Demets, C. Bucher, Electrochim. Acta 2019, 316, 7992.

[107] F. Li, M. Wang, S. Guan, Z. Huang, S. Liu, X. Li, X. Jiang, Q. Luo, J. Xu, J. Liu, Polym. Chem. 2019, 10, 5659-5664.
Text for Table of Contents

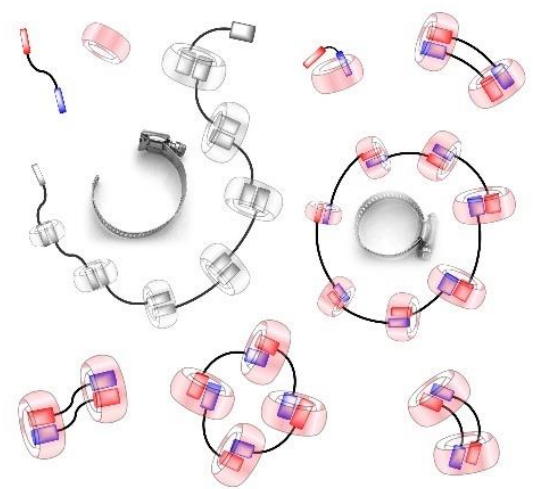

Xue, Yang, Ruibing Wang, ${ }^{*}$ Anthony Kermagoret, * and David Bardelang*

Page No. - Page No.

Oligomeric Cucurbituril Complexes: from Peculiar Assemblies to Emerging Applications

Cucurbit[8]uril can stabilize discrete host:guest n:n oligomers of controlled size and shape in water with properties, specific to the oligomers. We collected more than 50 examples and identified several factors explaining the formation of linear or cyclic oligomers and provide some rational to design new assemblies and target advanced properties. 